\title{
Consumption of Energy Drinks Among Lebanese Youth:A Pilot Study on the Prevalence and Side Effects
}

\author{
Manal Itany ${ }^{1}$; Batoul Diab ${ }^{1}$; Samar Rachidi ${ }^{1}$; Sanaa Awada ${ }^{1}$; Amal Al Hajje ${ }^{1}$; Wafaa Bawab ${ }^{1}$; \\ Pascale Salameh ${ }^{1, "}$ \\ ${ }^{1}$ Clinical and Epidemiological Research Laboratory, Faculty of Pharmacy, Lebanese University, Beirut, Lebanon \\ ${ }^{*}$ Corresponding author: Pascale Salameh, Clinical and Epidemiological Research Laboratory, Faculty of Pharmacy, Lebanese University, Beirut, Lebanon. Tel: +96-13385542, Fax: +96- \\ 11696600, E-mail: psalameh@ul.edu.lb; pascalesalameh1@hotmail.com \\ Received: April 7, 2014; Revised: May 18, 2014; Accepted: May 19, 2014
}

\begin{abstract}
Background: The new millennium has been together with a variety of synthetic and caffeinated high-energy drinks targeting the youth market. Energy drinks raise the level of energy and their consumption has been increased significantly worldwide.

Objectives: This research aimed to determine patterns of energy drink consumption and to assess the prevalence of adverse side effects among energy drink users.

Patients and Methods: A pilot cross-sectional study survey was undertaken on students aged between 13 and 30 years in private and public schools and universities in Lebanon over 5 months. Aself-administered questionnaire was used inquiring about sociodemographic characteristics, consumption patterns, attitudes and beliefs about energy drinks. Bivariate and multivariate analyses were conducted. Data was analyzed using SPSS 17 .

Results: We studied 1500 students (mean age: $18.92 \pm 1.85$; 51.3\% were males). The overall prevalence of energy drinks consumption was $63.6 \%$ (60.5\% were males), among which 50.5\% used alcoholic energy drinks. Respondents indicated that most consumed energy drinks were "Red Bull" and "Boom Boom" (70.9\% and 51.5\% respectively). In total, 64.5\% of participants believed the effect of these drinks in energizing the body, and $72.7 \%$ believed that they can stimulate intellectual capacities. In addition, $29.6 \%$ of consumers experienced at least one adverse effect, where tachycardia was reported in $21.1 \%$ of cases. On the other hand, desired effects felt after consumption were mostly pleasure (33.8\%). Males had a 3-time more risk of consuming such drinks compared to females (OR: 0.381, P< 0.001; 95\% CI: 0.300-0.484). Additionally, this analysis demonstrated a significant association between energy drinks consumption and regions outside Beirut (OR: 1.401, P: 0.006; 95\% CI: 1.103-1.781), medical field of work (OR: 0.376, P: 0.010; 95\% CI: 0.179-0.790) and higher personal income (OR: 1.317, P < 0.001; 95\% CI:1.117-1.553).

Conclusions: This study showed a high prevalence of energy drinks consumption among youth. The current results highlight the importance of education to prevent the consumption of energy drinks in excessive quantities and modifying some wrong perceptions regarding the benefits of energy drinks in youth.
\end{abstract}

Keywords: Energy Drinks; Alcohol Drinking; Students

\section{Background}

The new millennium has been together with a variety of synthetic and caffeinated high-energy drinks targeting the youth market (1). The term "energy drink" (ED) designates any product in the form of a drink or concentrated liquid (2), which claims to contain a mixture of ingredients such as caffeine, taurine, Guarana, vitamins B, and some others able to raise the level of energy and mental performance (3). Over the past 10 years, consumption of energy caffeinated beverages has been increased significantly (1). In addition, energy drink industry has been developed exponentially with almost 500 brands launched internationally in 2006, which most are sold without age restrictions (4). However, energy drinks typically attract young people. Recent studies among college students documented the prevalence of energy drink use as 39\% to $57 \%(5,6)$. Approximately $66 \%$ of consumers were $13-35$ years old. This attraction to energy drinks might be due to effective product marketing, peer influence, and lack of knowledge about their potential harmful effects $(5,6)$. Many harmful effects are attributed to these drinks and many cases of hospitalizations were reported by emergency physicians $(7,8)$. Adverse reactions and toxicity of high-energy drinks originate primarily from their caffeine content and the synergic effect of other ingredients (9). These effects might be due to the consumption of quantities of components that exceeds the maximum tolerated dosage per day $(1,3)$. Cardiovascular conditions following excessive energy drink consumption include heart palpitation, tachycardia, chest pain and dysrhythmias (10). Indeed, those beverages rich in exciting substances induce other side effects such as peripheral vasoconstriction, hypertensive effect (3), headache, anxiety, irritability, agitation, nausea, vomiting, abdominal pain, diarrhea, gastroesophageal reflux, heartburn and esophagitis (11).

Copyright @ 2014, Zahedan University of Medical Sciences; Published by Kowsar Corp. This is an open-access article distributed under the terms of the Creative Commons Attribution License, which permits unrestricted use, distribution, and reproduction in any medium, provided the original work is properly cited. 
The use of energy drinks seems to be increasing in Lebanon and their sale and use remain unregulated. In addition, there has been no research in Lebanon regarding the patterns of energy drink consumption and their side effects.

\section{Objectives}

In this pilot cross-sectional study, we aimed to determine the patterns of energy drink consumption and side effects in the youth Lebanese population.

\section{Patients and Methods}

\subsection{Study Design and Data Collection}

A pilot cross-sectional survey was conducted on students of three universities ( 1 public and 2 private universities) and eight schools ( 2 public and 6 private schools) in Lebanon. In Lebanon, the word "college" is equivalent to "school" (students stay at school until they obtain their baccalaureate (18 years old), while a university is a postschool institution (18 years and more). The study was performed over 5 months from February 2013 to June 2013. The final sample consisted of 1500 students. Inclusion criteria were being a full time university or school student, aged between 13 and 30 years, in a private or public institution, of both sexes. No exclusion criteria were considered.

\subsection{Tools and Procedures}

A self-administered, anonymous questionnaire in Arabic and French languages, developed by the investigators was distributed to students. It contained closed and openended questions. First, it was pilot-tested on 30 university students for further modifications of the questionnaire. The questionnaire contained items regarding current consumption, and knowledge and attitude about energy drinks. It consisted of 37 questions, divided into 3 parts. Ten questions were related to sociodemographic characteristics: age, gender, region and living status, field of study and work, and personal income. Fourteen general questions were related to energy drinks. Thirteen specific questions were about side effects of using energy drinks. Participants gave informed consent to participate in the study and were assured about the anonymity of questionnaires. Permissions were obtained from the schools administrations and the Ethics committee at universities prior to the initiation of study.

\subsection{Statistical Analysis}

Descriptive statistics, mainly mean values were used for continuous variables, and proportions were used for discrete variables. Chi-2 test was used to compare categorical variables. A Backward likelihood logistic regression was used whenever the dependent variable was dichotomous, and the independent variables are those showing association in the bivariate analysis at $\mathrm{P}<0.2$. In all logistic regressions, a non-significant Hosmer-Lemeshow test was obtained $(\mathrm{P}>0.05)$ to ensure an adequacy of the model. A P $<0.05$ was considered significant. Data was analyzed using SPSS, version 17.

\section{Results}

\subsection{Sociodemographic Characteristics}

A total of 1500 participants (51.3\% were males), aged 18.92 \pm 1.85 years (ranging from 13 to 30 years old) filled the questionnaire. The participants were divided in half between Beirut and other regions (Bekaa, South Lebanon, North Lebanon, and Mount Lebanon). They were distributed among schools (60.2\%), and universities (28.7\%). In total, $11.2 \%$ were graduated (23.7\% from medical and $76.3 \%$ from nonmedical fields), and most had a monthly personal income around $100 \$-300 \$(42 \%)$. Almost all were living with their families (93.3\%); 97.3\% did not have chronic diseases (Table 1).

\subsection{Consumption Prevalence and Knowledge About Energy Drinks Effects}

The prevalence of energy drink consumption among the surveyed participants was $63.6 \%(n=956)$. The mean age at first consumption was $15 \pm 3$ years as shown in Table 2. Most participants (51.1\%) consumed drinks lower than once per month. The mean number of cans consumed consecutively was $1.4 \pm 0.8$ cans. The most common reason and situation to consume energy drinks was in nightclubs (29.2\%). $70.9 \%$ of the respondents indicated that they usually drink "Red Bull@”. Others consumed brands of energy drinks as presented in Figure 1.

In total, $78.5 \%$ of participants considered this beverage as a drink that energizes and stimulates wakefulness, $15.7 \%$ as sports drink and $5.9 \%$ as a drink that stimulates the intellectual capacities. Regarding the knowledge about the side effects of these drinks, $53.4 \%$ believed that these drinks can affect the health, while $35.5 \%$ did not know the side effects and a minority (11.1\%) considered them as safe drinks. Among the participants, $40.7 \%$ indicated possible side effects, most of them insisted on their potential cardiac effect. The two most mentioned adverse effects by the participants were tachycardia (34.2\%) and cardiac disease (15.8\%).

\subsection{Adverse and Desired Effects Associated With the Consumption of Energy Drinks}

In total, 29.6\% of consumers experienced at least one adverse effect, while $70.4 \%$ did not. The adverse health effects occurred in consumers were tachycardia in $21.1 \%$, insomnia in $14.4 \%$, polyuria in $10.9 \%$, tremor in $9.7 \%$, headache in $8.7 \%$, flushing in $8.4 \%$, abdominal pain in $7.5 \%$, nausea in $6.8 \%$, vomiting in $4.2 \%$, agitation in $3.5 \%$, redness of the skin in $2.4 \%$ and pruritus in $0.5 \%$. Other effects reported from consumers were dyspnea, hypotension, nervousness and dizziness. There was also a case of hospitalization, reported by a participant in the survey, due to tachycardia associated with consumption of energy drinks. 
Itany $M$ et al.

Table 1. Sociodemographic Characteristics of the Study Population $^{\mathrm{a}}$

\begin{tabular}{|lc|}
\hline & Results \\
\hline Age, $\mathbf{y}$ & \\
\hline $13-18$ & $872 \pm 58.1$ \\
\hline $19-23$ & $461 \pm 30.7$ \\
\hline $23-30$ & $167 \pm 11.1$ \\
\hline Gender & \\
\hline Male & $769(51.3)$ \\
\hline Female & $731(48.7)$ \\
\hline Region & \\
\hline Beirut & $750(50)$ \\
\hline Other regions & $750(50)$ \\
\hline Living situation & $1399(93.3)$ \\
\hline With family & $35(2.3)$ \\
\hline Alone & $33(2.2)$ \\
\hline With a roommate & $33(2.2)$ \\
\hline Multiple dorm
\end{tabular}

\section{Number of people living together}

1-5

1185 (79)

$\geq 6$

$315(21)$

\section{Education}

$\begin{array}{lc}\text { College } & 903(60.2) \\ \text { University } & 430(28.7) \\ \text { Graduated } & 167(11.2)\end{array}$

Field of study

$\begin{array}{ll}\text { Medical } & 102(23.7) \\ \text { Nonmedical } & 328(76.3)\end{array}$

Work

$\begin{array}{ll}\text { Full time } & 177(62.5) \\ \text { Part time } & 106(37.5)\end{array}$

\section{Field of work}

Medical $\quad 40(14.1)$

Nonmedical 243 (85.9)

\section{Personal income, $\$$}

$\begin{array}{lc}<100 & 493(32.86) \\ 100-300 & 630(42) \\ 300-500 & 181(12) \\ >500 & 196(13.14)\end{array}$

\section{Chronic disease}

\begin{tabular}{lc} 
No & $1459(97.3)$ \\
Yes & $41(2.7)$ \\
\hline
\end{tabular}

${ }^{\mathrm{a}}$ Data are presented as Mean \pm SD or No. (\%).
Table 2. Characteristics of Energy Drink Consumers ${ }^{a}$

\begin{tabular}{|lc|}
\hline & Results \\
\hline Frequency of consumption & \\
\hline Rarely & $487(51.1)$ \\
\hline Often & $282(29.6)$ \\
\hline Regularly & $128(13.4)$ \\
\hline Daily & $57(6)$ \\
\hline Monthly expenditure, $\mathbf{L}$ & \\
\hline$<10.000$ & $677(71)$ \\
\hline $10.000-30.000$ & $213(22.3)$ \\
\hline$>30.000$ & $64(6.7)$ \\
\hline Consumption by a relatives & $119(12.5)$ \\
\hline Father & $61(6.4)$ \\
\hline Mother & $354(37.1)$ \\
\hline Siblings & $62(6.4)$ \\
\hline Others
\end{tabular}

\section{Consumption places}

Home

Restaurant/cafe/club

$486(25.8)$

At friend's house

$420(22.3)$

Public places/public garden

329 (17)

Beach

$54(2.8)$

University

$43(2.2)$

School

$33(1.7)$

\section{Consumption occasions}

In night clubs or evening

$404(29.2)$

Before a sport activity

$218(15.7)$

Long distance driving

$175(4.5)$

Examination period

$63(12.6)$

Thirsty

$110(7.9)$

At anytime

$413(29.8)$

Age, $y$

$15 \pm 3$

Number of cans consumed consecutive, cans

$1.4 \pm 0.8$

Figure 1. Consumption Frequency of Each ED Available on the Lebanese Market

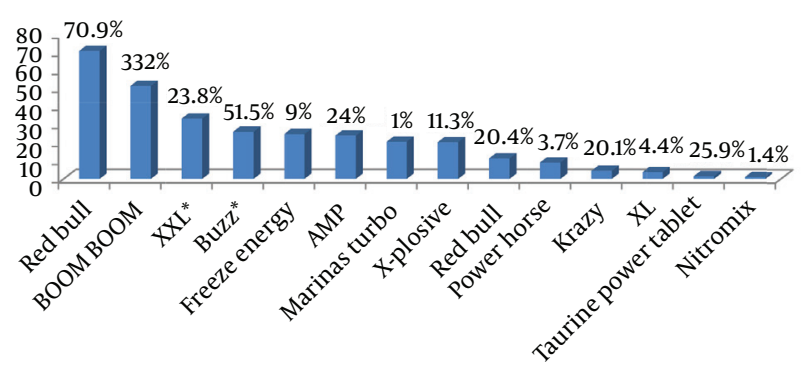

Available in nonalcoholic and alcoholic forms. 
Itany $M$ et al.

\begin{tabular}{|c|c|c|c|}
\hline & Consumers & Non Consumers & P Value \\
\hline Age, $y$ & & & 0.02 \\
\hline $13-18$ & $529(60.7)$ & $343(39.3)$ & \\
\hline $19-23$ & $313(67.9)$ & $148(32.1)$ & \\
\hline $24-30$ & $112(67.1)$ & $55(32.9)$ & \\
\hline Gender & & & 0.000 \\
\hline Male & $577(75)$ & $192(25)$ & \\
\hline Female & $377(51.6)$ & $354(48.4)$ & \\
\hline Region & & & 0.003 \\
\hline Beirut & $449(59.9)$ & $301(40.1)$ & \\
\hline Other regions & $505(67.3)$ & $245(32.7)$ & \\
\hline Number of people living together & & & 0.006 \\
\hline $1-5$ & $775(65.4)$ & $410(34.6)$ & \\
\hline$\geq 6$ & $179(56.8)$ & $136(43.2)$ & \\
\hline Field of study & & & 0.001 \\
\hline Medical & $23(57.5)$ & $17(42.5)$ & \\
\hline Nonmedical & $179(74.3)$ & $62(25.7)$ & \\
\hline Personal income, $\$$ & & & 0.000 \\
\hline$<100$ & $272(55.2)$ & $221(44.8)$ & \\
\hline $100-300$ & $411(65.2)$ & $219(34.8)$ & \\
\hline $300-500$ & $89(78.8)$ & $24(21.2)$ & \\
\hline$>500$ & $32(64)$ & $18(36)$ & \\
\hline ED definition & & & 0.007 \\
\hline Drink that energizes and stimulates & $759(64.5)$ & $418(35.5)$ & \\
\hline Wakefulness & $131(55.7)$ & $104(44.3)$ & \\
\hline Sports drink that stimulates intellectual capacities & $64(72.7)$ & $24(27.3)$ & \\
\hline Knowledge of ED side effects & & & 0.001 \\
\hline No & $128(76.6)$ & $39(23.4)$ & \\
\hline Yes & $493(61.5)$ & $308(38.5)$ & \\
\hline I do not know & $333(62.6)$ & $199(37.4)$ & \\
\hline Total & $956(63.6)$ & $546(36.4)$ & \\
\hline
\end{tabular}

Among participants consuming these beverages, 11.3\% mentioned dependency to such drinks. A bivariate analysis reported the association between feeling of pleasure (87.7\%) and dependency $(\mathrm{P}<0.05)$. Mainly the desired effects felt after energy drink consumption were mostly pleasure (33.8\%), gaining energy (33.8\%), wakefulness (17.6\%) and intellectual concentration ( $8.5 \%$ ).

\subsection{Combination of Energy Drinks With Alcohol}

The prevalence regarding energy drink consumption with alcohol combination among the surveyed partici- pants was $50.5 \%(\mathrm{~N}=481)$. The frequency of consuming energy drinks mixed with alcohol was as follow: always $24 \%$, sometimes $42 \%$ and rarely $34 \%$. The main type of used alcohol was vodka $77.5 \%$, and $15.6 \%$ reported that this combination was associated with adverse health effects such as nausea (25.3\%), tachycardia (20\%) and vertigo (16\%).

\subsection{Determinant Factors for the Use of Energy Drinks}

As shown in table 3, consumption was significantly higher among 19-23 age group (67.9\%) and males accounted 
Itany $M$ et al.

for the highest proportion (75\%). On the other hand, the bivariate analysis showed less consumption among participants from Beirut (59.9\%) compared to other regions (67.3\%). Participants living with 1-5 persons consumed more ED compared to participants living with equal to or more than six persons (65.4\% and $56.8 \%$ respectively). Moreover, consumption of energy drinks was significantly different across various fields of study, with the highest rate reported among participants of nonmedical field (74.3\% and 57.3\% respectively). Besides, a higher association was observed between personal incomes and drinking. Generally, consumers were people who did not know the health effects of energy drinks (76.6\%) or considered them as safe ones (62.6\%).

\subsection{Multivariate Analysis}

\subsubsection{The Impact of Various Factors on the Consumption of Energy Drinks}

Totally, $63.6 \%$ were found to be current consumers. Table 4 summarizes the predictive factors affecting the consumption of energy drinks in Lebanon. In multivariate analysis, gender was associated with energy drink consumption, females were less likely to consume energy drinks (ORa: 0.381, P < 0.001; 95\% CI: [0.3-0.484]).

Additionally, students majoring in medical fields were less likely to consume energy drinks compared to those of nonmedical fields (ORa: 0.376, P = 0.01; 95\% CI: [0.1790.79]). Moreover, a significant association was found between energy drink consumption and region for participants who lived in other regions versus those living in Beirut (ORa: 1.401, P = 0.006; 95\% CI: [1.103-1.781]). Finally, increasing income was associated with higher odds of energy drink usage (ORa: 1.317, $\mathrm{P}=0.001$; 95\% CI: [1.117-1.553]).

\subsubsection{The Impact of Various Factors on ED Adverse Health Effects}

In total, $29.6 \%$ of consumers declared that they had experienced an adverse effect from ED consumption. Multivariate analyses demonstrated significant higher risk of ED side effects and older age (ORa: 1.466, P < 0.001; 95\% CI: [1.187-1.811]). The same was found between the number of cans consumed consecutively and ED side effects (ORa: 1.223, P = 0.04; 95\% CI: [0.987-1.515]). Furthermore, incapability to stop drinking once the consumers started to drink was associated with greater odds of reporting ED side effects (ORa: 1.248, P = 0.02; 95\% CI: [1.031.511]). Another interesting finding was that consumption of other caffeine sources combined with ED was associated with increased risk of ED side effects (ORa: 2.297, P < 0.001; 95\% CI: [1.667-3.166]). Moreover, a greater association was found between the consumption during exam period and adverse effects ( $\mathrm{ORa}$ : $2.241 ; \mathrm{P}=0.02$; 95\% CI: [1.561-3.218]). Data of multivariate analysis is summarized in Table 5.
Table 4. Logistic Regression Analysis of Predictors of ED Consumption Among Participants

\begin{tabular}{|c|c|c|c|}
\hline \multirow[b]{2}{*}{ Male } & \multicolumn{2}{|c|}{ P Value Adjusted OR } & \multirow{2}{*}{\begin{tabular}{|c|}
$\mathbf{9 5} \% \mathbf{C I}$ \\
$0.300-0.484$
\end{tabular}} \\
\hline & $<0.001$ & 0.381 & \\
\hline Regions outside Beirut & 0.006 & 1.401 & $1.103-1.781$ \\
\hline Nonmedical field of study & 0.010 & 0.376 & $0.179-0.790$ \\
\hline Higher personal income & $<0.001$ & 1.317 & $1.117-1.553$ \\
\hline
\end{tabular}

Table 5. Logistic Regression Analysis of Predictors of Adverse Health Effect Among ED Consumers

\begin{tabular}{|c|c|c|c|}
\hline \multirow[b]{2}{*}{ Age } & \multicolumn{2}{|c|}{ PValue Adjusted OR } & \multirow{2}{*}{\begin{tabular}{|c|}
$\mathbf{9 5} \% \mathbf{C I}$ \\
$1.187-1.811$ \\
\end{tabular}} \\
\hline & $<0.001$ & 1.466 & \\
\hline $\begin{array}{l}\text { Number of cans consumed } \\
\text { consecutively }\end{array}$ & 0.046 & 1.223 & $0.987-1.515$ \\
\hline During exam period & $<0.001$ & 2.241 & $1.561-3.218$ \\
\hline $\begin{array}{l}\text { Incapable to stop once } \\
\text { started drinking }\end{array}$ & 0.023 & 1.248 & $1.030-1.511$ \\
\hline $\begin{array}{l}\text { Consumption with other } \\
\text { caffeine sources }\end{array}$ & $<0.001$ & 2.297 & $1.667-3.166$ \\
\hline
\end{tabular}

\section{Discussion}

The current study indicated that energy drink consumption is popular among Lebanese youth. In our study, 956 of 1500 participants (63.6\%) reported consuming energy drinks with a different frequency of consumption, which is higher compared to several investigations on college students reporting the prevalence of energy drinks use as $39 \%$ to $57 \%(5,6,12)$. On the other hand, this study was the first that estimated the prevalence and patterns of consumption among Lebanese youth. Our study is concordant with other studies who confirmed that young adults like to consume energy drinks. Oddy et al. found that $28 \%$ of $12-14$ years old, $31 \%$ of $15-17$ years old, and $34 \%$ of 18-24 years old participants reported regularly consumption of energy drinks (13).

A comparison between energy drink consumption habits of males and females in our study showed that a high percentage of the respondents were males (75\%), where males consumed 3 times more ED compared to females (OR: 0.381, P < 0.001; 95\% CI: 0.3-0.48). This finding of the present study is in line with other investigations indicating higher consumption among males $(5,12,14,15)$. A probable reason for the higher intake of energy drinks among males is advertisements, which primarily target young males as asserted by Miller. In addition, we found no differences in the prevalence of side effects and attitude towards energy drinks between sexes.

The American College Health Association reported that $71 \%$ of college students under survey reported insufficient sleep (16). In our study, $78.5 \%$ of participants defined energy drinks as beverage that energizes and stimulates wakefulness supporting the premise that college students use energy drinks to treat sleep deprivation while studying or 
partying. On the other hand, $15.7 \%$ considered this drink as sports drink and $5.9 \%$ as beverage that stimulates intellectual capacities. Such finding is not surprising, as Bonci (17) indicated that most people believed that consuming energy drinks is a fast means of obtaining 'extra energy' to undertake activities and speed up recovery from exercise. The findings of the present study corroborate with Malinauskas et al. findings (5), in which $65 \%$ of college students indicated consumption of energy drinks because they needed energy. Similarly, Oteri et al. (14) reported that energy drink consumption has become widespread among college students, particularly student athletes who meet both cognitive and physical performance demands.

Furthermore, drinking multiple energy drinks cans (37.7\%) and combination with alcohol (50.5\%) was a popular habit among energy drink users in our study. Our results showed that the favorite place for drinking was at home (27.5\%) or restaurant/cafe/club (25.8\%). This was in accordance with a survey conducted in the United States on a large cohort of students, which showed that consumption of energy drinks combined with alcohol was a common practice for $73 \%$ of regular users (14). These authors also showed that students, who regularly used these beverages, drank more than three cans each time. Another survey performed in Italy showed that $85 \%$ of participants used a mixture of alcohol and energy drinks and 36\% of participants consumed more than three cans (18).

Health implications of excessive intake of energy drinks were numerous in our results as reported by $29.6 \%$ of users. In total, $21.1 \%$ experienced tachycardia, $14.4 \%$ reported insomnia, $10.9 \%$ had polyuria, $9.7 \%$ had tremor and $8.7 \%$ had headache. The results of our study are comparable to those found in other studies. Seifert et al. reported that energy drink consumption was associated with tachycardia, dyspnea, headache fatigue and anxiety (19). On the other hand, our results demonstrated an association between the occurrence of adverse health effects and the increasing number of cans consumed (OR: 1.22, P = 0.046; 95\% CI: 0.98-1.52). Participants who consumed ED combined with other caffeine sources had 2 times more risk to experience adverse effects compared to those who did not drink other caffeine drinks with ED (OR:2.297, P < 0.001; 95\% CI: 1.67-3.17). Similar to our result, Strain et al. showed that the effects of caffeine are dose-related, with low to moderate doses of caffeine (20 to $200 \mathrm{mgs}$ ) producing increased happiness, energy, alertness, and sociability. Conversely, higher doses are more likely to produce undesirable effects, such as anxiety, nervousness, and upset stomach (20). Widely varying amounts of caffeine in energy drinks together with inadequate product labeling and marketing to youth increase the likelihood of caffeine overdose (i.e., caffeine intoxication), which can be medically problematic $(9,21-23)$.

Some possible biases could arise from the study methodology such as a selection bias. In this pilot cross sectional study, the sample was not taken randomly, because public university directors did not allow us to fill out the questionnaires during classes; hence, it was not possible to select a random sample. Therefore, the questionnaires were empirically distributed to students during recess hours. Our results could be affected due to under or over estimation of the expected association because some faculties could be more represented than others. In addition, we did not take enough samples from private university and public schools. Indeed, based on the descriptive statistics regarding age, we primarily had undergraduate participants. Therefore, findings may not be broadly generalizable.

The possibility of nonresponders bias cannot be excluded in this study and some participants did not complete the entire questionnaire. It was not possible to get detailed information of nonresponders. However, nonresponder bias did not affect our results, because missing value was less than $10 \%$. In addition, the delicateness of the subject increased the risk of false answers. The bias introduced by underreporting is possible, as the consumption behaviors such alcohol combination is a sensitive issue, and some students preferred not to reveal it especially females; this could cause an underestimation of the expected associations. While, males did not have a problem to indicate their consumption, because they liked to appear more mature and cool, which may lead to differential bias.

Another important limitation of this study was its cross-sectional nature, so causality or temporal relationships could not be inferred from the results, and future longitudinal researches would be necessary to investigate these issues. However, in the absence of other exhaustive studies in Lebanon and Arabic countries, these data provides a crucial starting point for such studies. To remove the confounding effect of several variables, we performed a multivariate analysis; however, we could not exclude the possibility of residual confounding due to variables that we did not evaluate. Our study also had some strong points; since we had a large sample size, we had no problem regarding the power of study. Furthermore, there was a significant dose-dependent association between energy drink consumption and related side effects. Moreover, since our results were much similar to those of recent studies, we have no reason to believe that this would have affected the validity of our results. Further studies are suggested to confirm our pilot findings.

Using energy drinks is a popular habit among students as we found that $63.6 \%$ of surveyed participants reported consumption of energy drinks. Alcohol-mixed energy drinks pose a particularly dangerous situation for young people, which needs more investigation. The current results of the study highlight the importance of health education to prevent the consumption of energy drinks in excessive quantities and modifying some wrong perceptions in young people regarding the benefits of energy drinks.

\section{Acknowledgements}

We are gratefully thanks for Lebanese University Administration. 


\section{Authors' Contributions}

All author contributed to the study design, data analysis and manuscript writing.

\section{Funding/Support}

This work was supported by the Doctoral School of Sciences and Technologies at the Lebanese University. It had no role in the study design, data collection, analysis and interpretation of results, writing of the report, and decision to submit the manuscript for publication.

\section{References}

1. Gunja N, Brown JA. Energy drinks: health risks and toxicity. Med J Aust. 2012;196(1):46-9.

2. Petit A, Levy F, Lejoyeux M, Reynaud M, Karila L. [Energy drinks: an unknown risk]. Rev Prat. 2012;62(5):673-8.

3. Wolk BJ, Ganetsky M, Babu KM. Toxicity of energy drinks. Curr Opin Pediatr. 2012;24(2):243-51.

4. Boissons énergisantes: risques liés à la consommation et perspectives de santé publique. Institut National De Santé Publique Du Québec; 2010.

5. Malinauskas BM, Aeby VG, Overton RF, Carpenter-Aeby T, BarberHeidal K. A survey of energy drink consumption patterns among college students. Nutr J. 2007;6:35.

6. Attila S, Cakir B. Energy-drink consumption in college students and associated factors. Nutrition. 2011;27(3):316-22.

7. Vivekanandarajah A, Ni S, Waked A. Acute hepatitis in a woman following excessive ingestion of an energy drink: a case report. Med Case Rep. 2011;5:227.

8. Di Rocco JR, During A, Morelli PJ, Heyden M, Biancaniello TA. Atrial fibrillation in healthy adolescents after highly caffeinated beverage consumption: two case reports. J Med Case Rep. 2011;5:18.

9. Reissig CJ, Strain EC, Griffiths RR. Caffeinated energy drinks--a growing problem. Drug Alcohol Depend. 2009;99(1-3):1-10.
10. Dobmeyer DJ, Stine RA, Leier CV, Greenberg R, Schaal SF. The arrhythmogenic effects of caffeine in human beings. $N$ Engl J Med. 1983;308(14):814-6.

11. Bawazeer NA, AlSobahi NA. Prevalence and Side Effects of Energy Drink Consumption among Medical Students at Umm Al-Qura University, Saudi Arabia. Inter J Med Students. 2013;1(3):104-8.

12. Miller KE. Wired: energy drinks, jock identity, masculine norms, and risk taking. J Am Coll Health. 2008;56(5):481-9.

13. Oddy WH, O'Sullivan TA. Energy drinks for children and adolescents. BMJ. 2009;339.

14. Oteri A, Salvo F, Caputi AP, Calapai G. Intake of energy drinks in association with alcoholic beverages in a cohort of students of the School of Medicine of the University of Messina. Alcohol Clin Exp Res. 2007;31(10):1677-80.

15. Ballistreri MC, Corradi-Webster CM. Consumption of energy drinks among physical education students. Rev Lat Am Enfermagem. 2008;16 Spec No:558-64.

16. Hoban M. American college health association national college health assessment spring 2006 reference group data report (abridged). J American College Health. 2007.

17. Bonci L. Energy drinks: help, harm, or hype. Sports Sci Exchange. 2002;1.

18. Pennay A, Lubman D, Miller P. Combining energy drinks and alcohol - a recipe for trouble? Aust Fam Physician. 2011;40(3):104-7.

19. Seifert SM, Schaechter JL, Hershorin ER, Lipshultz SE. Health ef fects of energy drinks on children, adolescents, and young adults. Pediatrics. 2011;127(3):511-28.

20. Strain EC, Mumford GK, Silverman K, Griffiths RR. Caffeine dependence syndrome. Evidence from case histories and experimental evaluations. JAMA. 1994;272(13):1043-8.

21. Persad LA. Energy drinks and the neurophysiological impact of caffeine. Front Neurosci. 2011;5:116.

22. O'Brien MC, McCoy TP, Rhodes SD, Wagoner A, Wolfson M. Caffeinated cocktails: energy drink consumption, high-risk drinking, and alcohol-related consequences among college students. Acad Emerg Med.2008;15(5):453-60.

23. Temple JL. Caffeine use in children: what we know, what we have left to learn, and why we should worry. Neurosci Biobehav Rev. 2009;33(6):793-806. 